\title{
Social Research and \\ Researchers in CGIAR: an \\ Underused Potential
}

\section{Robert Chambers}

This chapter will identify and explore some potential gains from social research and social researchers in the Consultative Group on International Agricultural Research (CGIAR). Social science includes economists, while social researchers and social research refer to non-economist social scientists and their work. The thrust is that new and changing perceptions, priorities and conditions open up new needs and potential. These are for 'practical theory, for being in touch with realities, for developing and spreading methodologies, for institutional learning and change and for questions and directions to sharpen the focus on poverty.

\section{Realities: the Context of Accelerating Change}

Li many dimensions affecting CGIAR and its centres, change is rapid and often accelerating. At the same time, the challenges have become more complex and more combined with local diversity.

The most significant change has been the redefinition of CGIAR's mission. The simple aim of increasing production is history. CGIAR is now guided by the goals of poverty reduction, which is to be demand driven, with the primary demand from poor people, and of environmental sustainability. Work undertaken is also meant to be of global significance.

These guidelines are made more challenging by the following:

- the powerlessness, lack of voice, dispersal and diversity of poor people;

- the multidimensionality of poverty, defined in the World Development Report 2000/2001: Attacking Poverty (World Bank, 2001) as 'pronounced deprivation of well-being', and including at least material lack, health, vulnerability, social relations and powerlessness (Alcamo et al., 2003: 73-76);

- rapid and often accelerating, rural change, as with, for example, migration, farming systems and cropping patterns, markets, feminization of agriculture, labour shortages (due to HTV/AIDS), social relations and climatic conditions;

- changing perceptions, aspirations and priorities of rural people, not least through the spread of mass communications, literacy, the work of non-governmental organizations (NGOs) and social movements; and - the increasing complexity, diversification and local variations of livelihoods, livelihood strategies and agroecosystems. The new mandate and tasks of the CGIAR impel a quantum leap to a new level of complication and difficulty. They demand a heightened awareness of the realities of poor people, their lives and livelihoods, and of potential causal pathways between what international agricultural 
research centres (IARCs) do and benefits to poor people. These are tall orders. Moreover, they axe aggravated by the need to work with increasing numbers of partners, by the transaction costs implied and by a funding squeeze. Taking the aims together with the conditions, the challenges are formidable and make a case for a radical rethink.

\section{Paradigms and Practical Theory}

Rethinking can be approached through practical theory about research and process.

The word 'paradigm' is overused but does fit this context. Paradigm refers to a pattern of concepts, beliefs, values, methods and behaviours that are mutually reinforcing. In this sense, the new mandate and tasks of CGIAR shift its dominant older and simpler paradigm of controlled and reductionist pipeline research to the new, more complex paradigm of the learning process. 1 This shift'can be characterized in many ways, for example, from Newtonian to post-Newtonian science (Uphoff, 1992). Comparing the two, pipeline research is more planned and executed in controlled conditions, with measurements to test hypotheses, with a beginning, middle and an anticipated end; less expected to fail; and aimed to lead to technologies that will then be disseminated. Learning-process research is more a voyage or journey in which errors and false leads, adaptations and changes of direction are expected, and learning and adapting are continuous and contextual. Learning-process research is underpinned by the practical theories of complexity and chaos. Characteristics of complexity theory and postmodern biology (Reason and Goodwin, 1999) make sense for learningprocess research. These include rich interconnections, reflecting the complexity of networks and relationships; iteration, including repeated cycles of action, reflection and learning; and holism in the sense of inclusiveness in the universe considered relevant. There are resonances with edge-of-chaos theory and a zone of creativity in which a few principles of behaviour and interaction generate emergent selforganization and insights.

The contrast is far from absolute, there are many exceptions, and much depends on individual personality and predispositions. To a degree, however, the approaches, methods and training of social research fit and are more comfortable with open-ended learning processes, and the approaches, methods and training of economics and the physical and biological sciences are more comfortable with the discipline of pipelines. This means that social researchers are generally better placed to catalyse and support the reorientation of CGIAR research to deal with the complexity, diversity and dynamism of the realities toward which it is pointed by its nsw mandate.

\section{Comparative Disadvantages of the CGIAR System}

In facing these challenges, the IARCs have disadvantages: 
- Isolation. Physical, social and political, isolation distances many (although not all) IARC scientists from poor people. The centres' mandates have sometimes been interpreted as to do 'upstream' research, with contact with the messy v/orld of actual farms and farmers the proper domain of national agricultural research systems.

- Public relations. Some at the February 2001 Costa Rica conference on 'Why has impact evaluation not had more impact?' attributed the funding problems of CGIAR in part to failures of presentation. The defensive reflex was not to change what (was done and how, but to communicate better. With some hyperbole it was remarked that CGIAR was 'surfing continuously on the froth of its own rhetoric'. Surf soon hits shallow water and the shore. As Peter Matlon said, 'Donors are not stupid'. It is substantive achievements, not presentation, that matter and convince.

- Language and litanies. When repeated too often, these lose credibility or induce complacency. In CGIAR's :iew strategy statement, $A$ Food Secure World for All: Toward a Neiv Vision and Strategy for the CGIAR (TAC Secretariat, 2000) phrases such as 'efficient and effective' begin to lose force with repetition and can even become self-defeating. To describe IARCs, as is customary, as 'centres of excellence' is a form of self-indulgent hubris.

- Professional mindsets. Ways of seeing things threaten to be a deep problem for the new directions. Powerful policy narratives can point research projects in wrong directions. The linearity of pipeline research thinking impedes iterative learning but persists as in the 2000 strategy statement, which sees the system as 'research suppliers' who 'deliver customized technologies'. Logframe thinking, wita its emphasis on time frames, targets and verifiable preset indicators, is more appropriate for infrastructure and physical things than for people, and narrows the space for creativity, serendipity end opportunism. The earlier 'piles-of-grain' orientation persists, with poverty and livelihoods less the starting point and core thari add-ons that top and tail documents without challenging and changing the basic frames and modes of thinking.

This is not to say that such mindsets are entirely unreasonable or wrong. In almost all contrasts drawn here, the question is not of 'either-or' but of a better balance of 'both-and'. But we have to ask whether commonly dominant ways of seeing and doing things represent and reinforce a momentum in what has now become a wrong direction, and whether the need is for more flexible and creative ability to identify and respond to opportunities.

- Inflexible and reduced core funding. The great value of core funding is the flexibility it allows to respond to changing realities, perceptions and opportunities. It is a sad paradox that precisely when 
CGIAR's mandate and context demand greater adaptability and opportunism, CGIAR's core funding should be shrinking.2 Impudent imagery of the old CGIAR comes to mind: of a supertanker whose weight and speed slow its change of direction, even when tugs push its bows; or of slow-moving dinosaurs, declining and doomed, when the future lies with the small and nimble protomammals at their feet (especially some of the younger and innovationseeking professionals?).

\section{Comparative Advantages through Social Researchers}

The comparative advantages of CGIAR are many and well known, not least its global reach, the positive aspects of its professional competence, its lack of rivals for producing certain global goods and the status that means that it can set norms and an example that others will emulate. These are usually considered in relation to the work of biophysical scientists and economists.

Less well recognized is CGIAR's comparative advantage through the work of social researchers, despite their low numbers in most IARCs (see Rathgeber, Chapter 3 this volume).

Much of this comparative advantage stems from the discipline of having to be relevant and make a difference. Unlike their academic counterparts, social researchers in CGIAR have to justify their work in practical terms, ultimately now toward achieving the system's poverty and environmental goals.

Social researchers have had a significant handmaiden role to biophysical scientists, as a sort of add-on or service provider to examine and deal with the social side of things. With the new mandate this role has to become wider and deeper, and no longer secondary but equal. This has perhaps already been achieved, or largely so, in centres such as the International Water Management Institute (IWMI) and the Center for International Forestry Research (CIFOR), which are concerned with the collective management of natural resources, and where the proportion of social researchers is higher than in other IARCs. But it is difficult to see how this can occur in IARCs that have more of a commodity orientation and very few social researchers (and astonishingly, in some cases - International Center for Agricultural Research in the Dry Areas (ICARDA) is one none at all).

Seeing, thinking about and trying to strengthen this significant service role can obscure the big contributions social researchers have made and can make in other ways and more in their own right. Here we cannot deny that they have already contributed outstandingly and on a considerable scale. An example is the generation and dissemination of practical theory through work on collective property rights (as through the CGIAR Systemwide Programme on Collective Action and Property Rights (CAPRi) network). 
Social researchers have a comparative advantage in contributing to achieving the mandate in three other areas, which have strengths and potentials:

- methodologies, as through the innovation and spread of forms of participatory action research (as through the Participatory Research and Gender Analysis network);

- institutional learning and change; and

- the questions social researcher? ask and the directions they point to.

\section{Methodologies}

First, the importance and potential influence and impact of new and better ways of doing things are almost everywhere overlooked or underestimated. Across the disciplines, this is a strange blind spot. Yet, new methodologies have great potential. New ways of doing things lead to new insights and new outcomes. Much has already been achieved by social researchers in CGLAR.3 An illustration is the early work of social anthropologists in the International Potato Center (CIP) (Rhoades, 1982 and Chapter 20 this volume). Six areas now stand out for their potential for methodological pioneering and spread. These can be thought of as potential high-yielding methodologies (HYMs).

- Bottom-up demand. Those whose demand is to provide the drive for 'demand driven' are in various combinations poor, vulnerable, excluded, voiceless and powerless. They are also diverse in their social relations, aspirations and livelihood strategies. To enable these groups to analyse and express their needs and priorities presents a special challenge. It requires sensitive research for them to help identify their research needs, to link these with what appears 'do-able', and to generate pro-poor innovations.

- Social innovations. These are institutions in the sense of rules, norms and accepted ways of doing things. One opportunity here is to learn how better to search for good social institutions. Another is to innovate ways of doing things, as already with farmer field schools, Integrated Pest Management, the comity de investigacion agrfcola local, or local agricultural research committee (CIAL) and many institutions in natural resources management. There should be potential for more social innovations and then for their spread. - Attitudes, behaviour, power and relationships. Little attention has been paid to attitudes, behaviour, power and relationships as components of good science, yet these are now recognized as significant dimensions of development, not least now that partnerships are such an important part of good practice (Groves and Hinton, 2004). The potential here would seem huge. The. dimensions are personal, professional and institutional. Behaviours and relationships for 'learning alliances' with partners are an example.

- Reflection and learning. Many methodological innovations and lessons 
pass unnoticed, unrecorded and unlearned from for two reasons: they are not recognized as significant; and professionals have no time for reflection, writing and sharing. Yet, social researchers in CGIAR, especially, produce a great deal of valuable innovation. 4 Beyond this, all professionals need time and space for reflection, learning and writing. There is scope here to adopt, adapt, invent, practise and evolve approaches' and methods. Examples are the write-shops of the International Institute for Rural Reconstruction in the Philippines, the reflection and review and downward accountability initiatives of ActionAid (ActionAid, 2000, 2001), immersion practices (Eyben, 2004; Irvine et al., 2004) and reflection retreats. A vital part of this is learning through the reflexivity of selfcritical awareness.

- Learning about learning, innovation, adapting and creativity. This is in part linked with the sociology of science and innovation, and includes learning about processes of innovation and change through reflection on experience. A contribution here could be a series of histories of innovation (see, for example, Douthwaite, 2002).

- Spread and influence. This area has perhaps the greatest potential, encompassing processes described as scaling up, scaling out, diffusion, dissemination, adoption, adaptation and impact. Practical theory about the spread and influence of methodologies is lacking, yet the CGIAR system already has much experience. This area offers a wonderful opportunity to better understand how good methodologies can be spread faster and better, ar.d how HYMs can be self-spreading and self-improving, with greatly augmented influence and impact. Several of these opportunities for HYMs are linked. Resolutely seized together, they might be powerfully transformative. Nor are they necessarily a full list. Development and spread of good HYMs might have an immense influence and impact on reducing poverty and enhancing livelihoods.

It would be a start to recognize clearly what has already been achieved. More could then be done to further evolve and spread the HYMs already developed. Space and resources could (and in my view, should) be made available for this. But beyond that, I sense a need for radical changes of thinking and practice in CGIAR if future potentials are to be exploited, and that such changes are latent, feasible and incipient in several centres.

\section{Institutional Learning and Change in CGIAR}

The second area where social researchers have a special new contribution to make is institutional learning and change (ILAC).

'CGIAR can't learn. It is not a learning organization', and 'The challenge proposals have galloped back to the 1980s', may be harsh remarks, and in conversation things are said with a sharpness that is rare in print. But they give pause for reflection on how CGIAR should change to 
become a learning organization, how the pressure of preparing challenge vJUU

proposals can avoid recession to reductionist pipeline research and how CGIAR can look forward resolutely with vision and imagination. For learning, as donors pointed out at the Costa Rica conference in February 2002, it would be good to analyse what has not worked, the dead ends and lessons that can be* learned from these as well as from successes. Creative and radical reflection, review and change have not been hallmarks of the CGIAR system. Rathgeber's survey of scientists (Chapter 3 , this volume) is cne of the rare pieces of research on CGIAR. That the mandate of International Service for National Agricultural Research (ISNAR) should have been management of national agricultural research systems, but not including the CGIAR centres themselves, was a bizarre and even arrogant omission. 'They need it, we don't', is selfnegating. Physician, heal thyself. Therapists need therapy as learning to help them help others. With ISNAR now submerged into International Food Policy Research Institute (IFPRI), this may be a good time to correct this omission for :he sake of substantive gains to CGIAR.

ILAC is a promising initiative in this direction. A small informal group began to coalesce around this theme at the Costa Rica conference. The IFPRI research on poverty impacts of CGIAR research (Adato and Meinzen-Dick, 2003) also pointed toward the potential for continuous reflection and learning during research processes. A workshop at IFPRI in 2003 took this further, and a Rockefeller grant made space for the ideas to be developed as a pilot initiative (Horton and Mackay, 2003; ISNAR 2003; Watts et al., 2003). Key elements are accelerated institutional innovation and critical self-awareness. 'Shortened, self-reflective learning cycles exploring the effectiveness particular approaches and processes could drive the rapid institutional change that CGIAR centres need to improve the contribution of science to poverty reduction and environmental sustainability' (Watts et al., 2003: 7). Four synergistic approaches have been proposed:

- developing a supportive external environment, especially among donors;

- fostering a culture of innovation, learning and change;

- reorienting management systems to encourage and celebrate risktaking, innovation and learning; and . '

- developing and enhancing individuals' awareness, knowledge and skills.

As a start, ILAC for CGIAR might include the following list, which is far from fully thought out:

- identification of initiatives already taking place;

- recruiting of more social researchers, including from management science; !

- research, especially reflective and participatory action research, on the system and centres; 
- reflection by social and biophysical scientists on the histories of research programmes and relating them to follow through what they find out in the field; $\mathrm{J}$

- documentation and sharing of experience and networking; and - provision of regular opportunities for self-critical reflection, learning and writing, especially about processes and methodologies.

Social researchers have no monopoly of ability and orientation for these activities, but their skills and leavening, with the diversity of insights they can bring, will make a major contribution. Social researchers' collegial participation, facilitation and at times, leadership will be essential ingredients.

\section{Questions, Systems and Directions}

A third gain from social researchers is the questions they can and should ask, and the directions and content of research that follow from them. These questions relate not only to methodologies and ILAC but also to aspects of reality that other disciplines may overlook, underestimate or be unable to research and take adequately into account. These questions apply to much that concerns people rather than things, organisms and ecosystems. Arguably, the human, institutional and political dimensions are so important that social researchers should be as many as other kinds of researchers. IARCs that are most concerned with collective action and management of natural resources - notably International Center for Living Aquatic Resources Management (ICLARM, fisheries); International Water Management Institute (IWMI, water); and CIFOR (trees) - do, and properly so, have higher proportions of social researchers. But their numbers are low, derisory or nil in other centres, and in consequence the critical questions that have to be asked and answered, with the pro-poor mandate and the context of complexity, diversity and dynamism noted above, may not be asked. At a general level, social scientists (including economists) have a special responsibility with the pro-poor orientation to keep on again and again asking the questions they are best placed to ask, and which enlarge the agenda of relevance to make it mora realistic.

There are many questions, but one is overarching and has to be asked again and again, the answers probed and researched and the findings acted upon with frequent iterations: who gains and who loses? Following on from this, how can poor people gain more and lose less? The question leads straight into the messy, complex realities of 370 Robert Chambers people, social institutions, bureaucratic dynamics, corruption and politics. These realities are part of the holism of complexity and chaos theory. They cannot be left out, and they are where the special skills and insights of social researchers are needed.

The cost of not asking this question would be a degree of wild aiming and blind lottery in the relevance and impacts of biophysical 
research. Perceptive donors will always be asking the question. The CGIAR system needs the capacity to answer it, ex-ante and especially iteratively during research processes, and not just ex-post. Only then can the CGIAR system approach its huge potential for reducing poverty.

\section{Conclusion}

In addition to their accepted roles in support of biophysical scientists, CGIAR social scientists should be augmented for an additional reason: to increase effectiveness and efficiency in achieving the system's mandate. This reason relates to paradigms, practical theory, methodologies, ILAC, questions, systems and directions. Social researchers do not have a monopoly of expertise in these areas. Leadership and contributions can come from professionals in any discipline if they have the personal orientation and commitment. All the same, social researchers, from the nature of their disciplines, training and the questions they ask, do have a comparative advantage. The marginal gains from having more good social researchers in the CGIAR system should, therefore be high and, subject to personality and personal orientation, higher than the marginal gains from more biophysical scientists or economists. The question is not of alternatives, but of case-by-case realism. Unfortunately, for many reasons, when funds are short the social researchers are the ones axed, not least because their contributions are less tangible and visible. Conversely, when funds are more abundant, social researchers are not necessarily given priority in recruitment. If the CGIAR system is to fulfill its new mandate, and achieve anything like its potential, this has to change. If it is serious about poverty, the system has to better balance the disciplines.

Taking these ideas as starting points (and surely to be modified and augmented in ongoing processes of learning), increasing the number of social researchers would enable the CGIAR centres to do the following: - play to their comparative advantage and better fulfill their comparative responsibility;

- better reduce poverty and enhance the livelihoods of their poor clients;

- be more credible (and to support the chorus, effective and efficient) by becoming self-critical learning organizations;

- be more exciting, and so able to recruit and keep more creative and innovative professionals; and

- be more likely to be funded.

For many years it has been a mystery to me why donors do not fund the CGIAR more generously. Now more than ever, with the poverty focus, the benefits of additional funding should be high indeed. This view is being reinforced and substantiated by the evidence presented in this volume of what social researchers; have been doing and the contributions they have made. The potential for social research in the CGIAR 
system remains vastly underrealized. The likely benefits of additional

funding to CGIAR would be considerably higher if this meant more good

social researchers encouraged and enabled to work creatively with a propoor

orientation on the themes outlined above.

To be serious about poverty, CGIAR has to be serious about social

research.

\section{Notes}

1For other related dimensions, described as frameworks for development practice with two columns under the headings of from things and expanded to include people, see Watts et al. (2003: 8).

2 In the Participation Group in the Institute of Development Studies (IDS), Sussex, UK, we and our work have benefited from the willingness of our consortium of donors to include a budget head of $10 \%$ for 'unanticipated opportunities'. This has encouraged and allowed us to see and seize the unexpected opportunities that can be anticipated in our rapidly changing world. CGIAR does not seem to have equivalent flexibility. 3I became more aware of these during the first 2 days of the conference and will not list them here. But the contribution over the years has been remarkable, and the impact on how national agricultural research system, non-governmental organizations and others work has been immense, not least in participatory approaches and methods.

4This became more evident than ever in the first 2 days of the conference, in almost every presentation.

\section{References}

ActionAid (2000) ALPS: Accountability, Learning and Planning System.

ActionAid, London, 28pp. Available

online: www.actionaid.org/

resources/ pdfs/alps.pdf

- ActionAid (2001) Notes to Accompany ALPS. ActionAid, London, 105pp. Available online: www.actionaid.org/resources/pdfs/ alps_notes.pdf $372 \boldsymbol{n}$ uucl t w/ /a/ $\left(\boldsymbol{I t}-\mathrm{y}^{\wedge} \boldsymbol{i}\right.$ o Adato, M. and Meinzen-Dick, R. (2003) Assessing the impact of agricultural research on poverty and livelihoods. Quarterly Journal of International Agriculture 42(2), 149-166.

Alcamo, J. et al. (2003) Ecosystems and Human Wellbeing: a Framework for Assessment. Island Press, Washington, DC, 245 pp. 
Douthwaite, B. (2002) Enabling Innovation:

a Practical Guide to

Understanding and Fostering

Technological Change. Zed

Books, London and New York, 266 pp.

Eyben, R. (2004) Learning from Poor

People's Experience: Immersions,

Policy Briefing. IDS Sussex,

Brighton, UK, 4 pp.

Groves, L. and Hinton, R. (eds)

(2004) Inclusive Aid: Changing

Power and Relationships in International

Development Earthscan,

London, 237 pp.

Horton, D. and Mackay R. (2003)

Innovative approaches for evaluating

agricultural research and

development, Special Issue, Agricultural

Systems 78(2), 119-336.

Irvine, R., Chambers, R. and Eyhen,

R. (2004) Learning from Poor People's

Experience: Immersions,

Lessons for Change Series No. 13.

Institute of Development Studies,

Sussex, UK, 35 pp.

ISNAR (2003) Institutional Learning

and Change: a CGIAR Pilot Initiative.

ISNAR, The Hague, Netherlands,

6 pp. Available online:

d.horton@cgiar.org

Reason, P. and Goodwin, B.C. (1999)

Toward a science of qualities in

organizations: lessons from complexity

theory and postmodern

biology. Concepts and Transformations

4(3), 281-317.

Rhoades, R. (1982) The Art of the

Informal Agricultural Survey.

International Potato Center, Lima,

Peru, 40 pp.

TAC Secretariat (2000) A Food

Secure World for All: Toward a

New Vision and Strategy for the

CGIAR. TAC Secretariat, FAO,

Rome, 40 pp. 
Uphoff, N. (1992) Learning from Gal Oya: Possibilities for Participatory Development and Post-Newtonian Social Science. Cornell University Press, Ithaca, New York, 448 pp. Watts, J., Mackay, R., Horton, D. Hall, A., Douthwaite, B., Chambers, R. and Acosta, A. (2003)

Institutional Learning and

Change: An Introduction. ISNAR

Discussion Paper 03-10, International

Service for National Agricultural

Research, The Hague,

Netherlands, 19 pp.

World Bank (2001) World Development

Report 2000/2001: Attacking

Poverty. The World Bank,

Washington, DC, 335 pp. 